\title{
Fuentes neoplatónicas y hermetismo en la heterodoxia de la seglar Ana de Zayas (Puebla de los Ángeles, 1690-1696)/
}

\author{
Neoplatonic Sources and Hermeticism \\ in the Laywoman Ana de Zayas's Heterodoxy \\ (Puebla de los Ángeles, 1690-1696)
}

\section{Concepción Zayas}

Benemérita Universidad Autónoma de Puebla, México

Se analizará la influencia de fuentes neoplatónicas y herméticas en la heterodoxia de la seglar novohispana Ana de Zayas a través de los escritos que ella dirigió, a finales del siglo XVII, a los sacerdotes de su ciudad, la Puebla de los Ángeles. Dichos textos fueron la causa de que en 1694 se iniciara contra ella un proceso inquisitorial por alumbradismo. Su caso se desarrolla en un contexto cultural empapado de hermetismo, como se aprecia en las obras de sus contemporáneos Carlos de Sigüenza y sor Juana Inés de la Cruz. Más allá del mero estilo literario, Zayas es un ejemplo de cómo estas líneas filosóficas tenían una repercusión en formas heterodoxas de concebir y vivir la religión.

Palabras Claves: Filosofía; Religiosidad; Heterodoxia novohispana.

We will analyze the influence of hermetic philosophy in New Spain secular Ana de Zayas' religious heterodoxy. The neoplatonic sources from she fed her thought pervaded the documents she addressed to some priest in seventeenth-century Puebla de los Angeles. Such texts caused that in 1694 she was charged of alumbradismo. Her trial occurred within a milieu in which hermeticism was cultivate for some intellectuals such as Carlos de Sigüenza and Sor Juana Ines de la Cruz. Behind her literary style, Ana de Zayas is a good example of how those philosophical currents had a direct effect in the heterodox ways to conceive and life the religion.

KEYwords: Philosophy; Religiosity; Heterodoxy's New Spain. 


\section{Alias la Paloma, la Serpiente, la Salamandra...}

¿Fue el hermetismo, o su mixtura de saberes afines, ${ }^{1}$ solamente un estilo de moda en la Nueva España? Al parecer, no. Estas filosofías sirvieron para que algunos clérigos criollos justificaran sus ideas patrióticas ${ }^{2}$ y específicamente los jeroglíficos se usaron para transmitir un mensaje político. ${ }^{3}$ Según More, Carlos de Sigüenza entendió que al poder político se le debía hablar a través de jeroglíficos, como lo demuestra su arco triunfal erigido en 1680 para celebrar la entrada del virrey, marqués de la Laguna. ${ }^{4}$

Durante el XVII el disimulo y la representación simbólica fueron un recurso vital; ciertos valores políticos, religiosos o filosóficos sólo podían expresarse alegóricamente y su interpretación se reservaban a un grupo social reducido. Metáforas, emblemas y jeroglíficos fueron empleados para mostrar de un modo alusivo e indirecto principios de la filosofía natural moderna, la alquimia espiritual, la magia natural y la religión. ${ }^{5}$

El texto que citamos a continuación, escrito en 1695, fue expresamente dirigido a un sacerdote de la Puebla de los Ángeles y elaborado por una novohispana que solía firmar con herméticos alias como la Salamandra, la Paloma, la Serpiente, el Águila caudal o la Dama de Dios. Como se verá, el escrito contiene frases como «el que pierde el silencio pierde el juego», o «nadie ha de saber por qué reñimos», las cuales aluden a un silencio y un secreto donde aparecen involucrados sacerdotes y órdenes religiosas. Vale recordar que aludir a un secreto quizá era la mejor manera de diseminar ciertas ideas, el velar y mostrar pudo haber sido el poder más subversivo. ${ }^{6}$

Estos son los escogidos para el Juego de armas, y vuestra reverencia debe de pensar que no son muchos. ¿Ha visto vuestra reverencia unas cuchilladas en una calle, que

1 La principal característica que definió al movimiento hermético del Renacimiento era su visión del cosmos en conexión con una red de fuerzas mágicas con las que el hombre podía operar. Yates, 1999, 43-50; también Copenhaver, 1988b, 83. Acerca de estas corrientes, ver Ingegno, 1990; también Wallace, 1990.

2 Cañizares, 2003.

3 Ver Neptuno alegórico de sor Juana, o el Teatro de Virtudes Políticas de Sigüenza, sus emblemas sugieren la conducta virtuosa que se espera del gobernante o, incluso, las obras materiales que habrán de atenderse durante su mandato. Selig, 1968, 831-837; también Alatorre, 2010, 270-271. Docenas de ejemplos del sincretismo novohispano y cómo el conocimiento neoplatónico renacentista se aplicaba a exequias, arcos triunfales y todo tipo de emblemas en Osorio, 1993. En la Puebla de Zayas, ver la interpretación de Galí, 2008, 705-712.

4 More, 2002, 51 y 59

5 Vermeir, 2012.

6 Ibidem, 186. 
siendo dos los de la pendencia, se junta el mundo a ver y a saber la causa de la riña? Pues así han de ser estas cuchilladas, pues vuestra reverencia y yo somos los de la cuestión y todo el mundo ha de venir al ruido; y es el caso que nadie ha de saber por qué reñimos vuestra reverencia y yo aunque nos matemos a estocadas en la plaza. Porque el que pierde el silencio pierde el juego (esto es, el que me dijere lo que siente) especialmente vuestra reverencia que es el que está muy cerca de entrarse en la puerta de mi corazón, y esta puerta tiene el umbral del silencio [...] El clarinero corre a media rienda toda la plaza dando aviso de que se empiezan las fiestas, ¿y yo veo que el padre Canela huye a carrera abierta? [...] Dirá vuestra reverencia, el clarinero no corre. Respondo que vuestra reverencia ha de correr más que ninguno, pues ha de correr toda la plaza; y esto en círculo perfecto ${ }^{7}$ dando aviso a todas las religiones y después a todo el mundo; las religiones de monjas se siguen tras de las de frailes y yo lo iré explicando. Besa la mano de vuestra reverencia su indigna hija y madre que en Dios le ama. El Águila caudal. ${ }^{8}$

El escrito aquí citado muestra los guiños herméticos que usa la autora tanto en sus alias como en el contenido de sus textos. Estos implican una complejidad donde se involucra tanto el poder político como una particular religiosidad generada entre las capas cultas; debido a que la autora de tan enigmático mensaje fue procesada por la Inquisición y, al mismo tiempo, fue una mujer que se codeaba con los hombres más doctos de la urbe y protegida por poderosas figuras de la Iglesia. El verdadero nombre de esta «Serpiente», «Paloma» o «Salamandra» era Ana de Zayas, quien fue hija de un arquitecto de la Puebla imperial.

Probablemente nacida hacia 1650, a Ana de Zayas se le abre un proceso inquisitorial en la categoría de alumbrada vehemente en 1694. El proceso queda inconcluso por razones hasta ahora desconocidas para nosotros. En el tiempo cuando la Inquisición seguía sus pasos, doña Ana estaba separada de su violento marido y su única hija se encontraba ya enclaustrada en

7 Dios como círculo en Sor Juana, según la Hieroglyphica de Valeriano (Florencia, 1556), en Buxó, 1998, 247. Círculo y jeroglíficos en sor Juana, Bénassy, 1983, 149.

8 Archivo General de la Nación (AGN), Inquisición, 692, expediente 2, 258. También Archivo Histórico Nacional (AHN), Inquisición, 1731, expediente 34, «De los diferentes papeles de Ana de Zayas», 111. El destinatario de este escrito, el franciscano Maximiliano de Pro, recibió el texto aproximadamente el 10 de enero de 1695, y dos semanas después levantó una denuncia ante el Santo Oficio de Puebla. Desconocemos por qué el proceso contra Zayas quedó inconcluso, sabemos que se inició en Puebla en 1694, se remitió a la ciudad de México y finalmente al Tribunal español. Los escritos de Zayas están perdidos en su mayoría, algunos han llegado hasta nosotros transcritos por los miembros del Santo Oficio. Excepto un cuadernillo de una docena de páginas, de puño y letra de la autora, conservado en el AGN y que no se envió a España. Gran parte de este material no tiene fecha, salvo algunos documentos titulados — siguiendo a Teresa de Ávila— «Cuentas de mi conciencia» fechados entre 1692 y 1699. 
un convento; 9 ambos acontecimientos en la vida familiar de doña Ana fueron posibles gracias al apoyo moral y económico que recibió de sus protectores, influyentes jerarcas de la Iglesia.

Uno de ellos fue el famoso amigo de sor Juana Inés de la Cruz (16511695), el obispo de Puebla Fernández de Santa Cruz (1637-1699), quien autorizó a Zayas a separarse de su consorte, como la ayudaría también para impedir que la Inquisición la tomara presa en las cárceles secretas. ${ }^{10}$ Por otro lado, fue gracias a otro jerarca religioso que doña Ana pudo, contra la voluntad de su marido, conseguir el ingreso de su hija al convento. Este protector de Zayas era Ambrosio de Odón, quien durante la última década del XVII fuera dos veces provincial jesuita y rector del Colegio Máximo. ${ }^{11}$ Otro renombrado miembro de la Compañía que tuvo un papel protagónico en la vida de Zayas fue Alonso Ramos, rector del Colegio del Espíritu Santo de Puebla. ${ }^{12}$ Tristemente conocido por el escándalo que produjo la prohibición de los tres tomos que él escribió sobre la beata de Puebla, Catarina de San Juan: Prodigios de la Omnipotencia en la vida de la venerable Catarina de San Juan, ${ }^{13}$ cuyo primer volumen (publicado en 1689) fue puesto en el índice de libros prohibidos por la Inquisición española en 1693, para prohibirse totalmente hacia finales de $1696 .{ }^{14}$ Tal golpe para la

9 Desconocemos las causas y fecha de su muerte. Su caso lo he dado a conocer en varios artículos: Zayas, 2001, 2006 y 2007. Fuera de estos trabajos, no hay análisis exhaustivos sobre ella, más que breves referencias como en Rubial, 2006, 58-59 y 79. Comento brevemente algunos datos que habría que rectificar en otras referencias a Ana de Zayas: el denunciante de esta mujer, Alonso de Cristo, arguye que ella es una persona cuerda y por eso debe ser procesada, no porque esté separada de su marido. En este sentido la interpretación de Jaffary es incorrecta (Jaffary, 2002, 68; y 2004, 71, 72, 95-96 y 151-152). Zayas tampoco fue sentenciada, ni penitenciada como refiere Medina (1987, 334), ya que en octubre de 1698 su expediente se remite a Madrid, especificándose «inconcluso». Tampoco coincidimos con las conclusiones, a nuestro parecer, precipitadas, de Vallejo (2005).

10 Zayas, 2001. La ayuda del obispo a Ana de Zayas abre una nueva valoración sobre la figura del prelado. En esta línea ver Galí, 2001, y Peña, 2012.

11 Natural de Zaragoza, España, llegó a México en 1665 con 23 años. Desde 1682 es operario en Puebla, en 1686 pasa a Guatemala, de 1689 a 1693 es provincial e inmediatamente después rector del colegio máximo de San Pedro y San Pablo de la ciudad de México. En 1696 es propósito en la Profesa, en1699 vuelve como rector al Colegio Máximo y a provincial por segunda vez entre 1702 y 1703. Muere en Puebla el 27 agosto de 1716 (Hernández Palomo, 2005; González Rodríguez, 1998). En 1692, siendo provincial Odón, éste apoyó económicamente a doña Ana para que su hija, Ángela María de la Defensa, ingresara al convento de la Santísima Trinidad. AHN, Inquisición, 1731, exp. 34, 45-47.

12 Ramos había llegado a México en 1658, siendo un estudiante de teología. Archivo General de Indias (AGI), Contratación, 5431, n. 5.

13 Ramos, 1689-1691. Catalina de San Juan inspiró otras tres hagiografías, la del también jesuita Aguilera, 1688, y la del bachiller Castillo Graxeda, 1692.

14 Desde 1692 la Inquisición española ya había prohibido dos de los tres volúmenes totales (Myers, 2003, 68; también Morgan, 2000). 
Compañía, y concretamente para quien fuera uno de los principales confesores de Zayas, se gesta en torno a los mismos años que a ella se le denuncia por alumbradismo para luego seguírsele un proceso inquisitorial.

De las muchas preguntas que el caso puede despertar, aquí abordaremos sólo dos temas principales y una misma fuente subyacente a ambos: el neoplatonismo. La primera cuestión es con relación a la clasificación específica donde los inquisidores encuadran la heterodoxia de Zayas: alumbradismo en la categoría de vehemente. ${ }^{15}$ Ésta, debido a la instrucción intelectual de doña Ana, da la clave sobre un tipo concreto de heterodoxo, que no es el pícaro ni el embustero de escasa o nula formación letrada. Nuestra investigación podría aportar datos sobre el hecho de ser un alumbrado vehemente con relación a las raíces filosóficas y doctrinales donde se enraíza el alumbradismo español, una herejía que surgió a principios del XVI en Guadalajara, España, en un contexto contagiado de humanismo e ideas de Reforma. Bajo esta perspectiva histórica explicaremos particularidades importantes de la heterodoxia de Zayas y su conexión con posturas doctrinales ligadas más al neoplatonismo renacentista que al cristianismo ortodoxo.

El segundo tema a desarrollar es el lenguaje hermético con el que esta mujer se dirigió a los sacerdotes de su ciudad, el estilo velado de sus escritos la distingue de otros escritores heterodoxos, acusados también de ser vehementes sospechosos de alumbradismo. ${ }^{16}$ Doña Ana presenta asimismo un cuadro muy diferente al de sus coetáneas, quienes narraban sus experiencias de unión con Dios por orden de su confesor. ${ }^{17} \mathrm{~A}$ diferencia de ellas, Zayas hace suya la libertad de escribir a los sacerdotes con la clara intención de adoctrinarlos. Por otra parte, el hermetismo principalmente se ha tomado en cuenta como un recurso estético de la obra literaria de sor Juana Inés de la Cruz, o como una posible fuente de su inquietud científica..$^{18}$ Pero

15 Aplicamos el término heterodoxo como: «Heresy is not merely the holding of opinions inconsistent with orthodoxy, but presupposes obdurate persistence in such error; it is thus a moral state as well as the holding of false (heterodox) beliefs. This obduracy can manifest itself not only by refusal to abandon false doctrine, but also by the extension and development of orthodox positions beyond the limits sanctioned by the Church» (Maclean, 2005, XVIII). Con relación al proceso contra Zayas, ver Dictamen de José Sánchez y Diego Trujillo, AHN, Inquisición, 1731, exp. 34, 40.

16 Ver casos de alumbradismo en el AGN, Inquisición, vols. 43, 68, 450, 522, 664, 693 y 710 711 (años 1680-1700).

17 Tema ampliamente tratado en Myers, 2003. Casos de monjas poblanas, su escritura y relación con el confesor: Loreto López, 2002 y 2006; Lavrin, 2008, 317-326.

18 Trabulse, 1997, 296. Igualmente, los diversos trabajos que sobre la monja jerónima ha realizado Olivares han encontrado semejanzas entre ella y pensadores erasmistas, y coincidencias también con ciertas nociones mágicas de Giordano Bruno (Olivares, 2000 y 2010). 
habría que empezar a plantear el hermetismo de estas mujeres tan particulares como un discurso que pudo ser al mismo tiempo fuente, medio y hasta protección con relación al poder.

El caso de Zayas, su lenguaje velado, podría abrir una nueva discusión sobre las maneras de encubrir o guardar secreto como vía para adentrarnos a estructuras de autoridad, grupos de élite, y censura menos obvias que la Inquisición. ${ }^{19}$

Las dinámicas de velar o revelar conducen a filosofías que marcaron pautas en la vivencia de la religión o el saber científico, como ha estudiado Vermeir con relación al filósofo hermético e ilustrísimo miembro de la Compañía: Atanasius Kircher. Éste da una clave en las expresiones oscuras con las que Zayas transmitió su mensaje, reservado a la élite que podía descifrarlo. La intolerancia religiosa forzó a muchos autores a usar una máscara, la Nueva España es parte del movimiento barroco mundial caracterizado por apertura y secreto, ocultamiento y revelación. ${ }^{20}$ Más allá de las fronteras, las redes de expansión por las que el conocimiento hermético llegó hasta esta seglar de la Puebla Imperial, son las mismas que permitieron a los jesuitas tener presencia en gran parte del globo terráqueo. Tales rutas no fueron sólo físicas, ya que afectaron la concepción de la ciencia y la religión. ${ }^{21}$

\section{Una alumbrada, o dejada, vehemente}

Hacia 1520 en Guadalajara, España, surgió la secta de los alumbrados, quienes se distinguieron de otros movimientos reformistas de la época por su práctica ascética: el dexamiento. ${ }^{22}$ Aproximadamente ciento se-

19 El tema no ha sido tratado con relación a la Nueva España. Si bien en otro contexto, arroja luces sobre estructuras de poder que - bajo sus propias características - pudieron existir en el México colonial: Griffiths, 1977, 925-951; también Luthy, 2005, 90-103.

20 «Religious intolerance forced even celebrated philosophers such as Newton to develop elaborate strategies to dissimulate their beliefs [...] Everyone was wearing a mask, and as Shakespeare, Calderón, Molière, and many other authors remarked, we all play our different roles on the stage of the world». Vermeir, 2012, 23-24.

21 Alonso Ramos también juega con una noción dual de las experiencias visionarias de Catarina de San Juan, trazando una ruta física y otra moral o espiritual (Molina, 2004, 373). Rutas espirituales y materiales, ver también Lo Sardo, 2004, 58-62; Gorman, 2004.

22 «Cuyo nombre específico es el de quietud o abandono» (Márquez, 1980, 132). Siguiendo a Márquez, mantenemos la ortografía original sólo de éste término, el resto está ortográficamente actualizado. Ver también Hamilton, 1992, 31, y 2010. 
tenta años después de que en 1525 el Edicto de Toledo, España, condenara el dexamiento, éste reaparece en los escritos de doña Ana, referido idénticamente a los primeros alumbrados: como sinónimo de silencio mental y abandono a la voluntad divina.

Aun cuando Zayas fuera un caso aislado, el hecho prueba que algunos movimientos heterodoxos del XVI, ligados al humanismo español o sus corrientes afines, ${ }^{23}$ pervivían en la Puebla de finales del XVII. Falta por descubrir el canal que condujo a Zayas al dexamiento, ¿cómo supo ella la denominación exacta que siglos atrás habían empleado los primeros alumbrados españoles? Hasta este punto de nuestra investigación, a lo largo del XVII no hemos hallado otro caso en los archivos inquisitoriales que haga referencia explícita al dexamiento.

Vale observar que los mismos miembros del tribunal novohispano que dictaminaron los escritos de Zayas no reparan en el vocablo dexamiento como motivo de censura ni lo relacionan con el basto revoltijo herético que para entonces aglutinaba el término alumbrado (espíritu erróneo, iluso, ${ }^{24}$ blasfemo, pervertido, curandero y ermitaño) ${ }^{25}$ Los propios inquisidores olvidaron o desconocían que la práctica del dexamiento fue específicamente condenada en 1525 en el edicto contra los alumbrados. Hacia 1690, al Santo Oficio no le preocupaba el dexamiento, sino otra herejía estrictamente contemporánea y perseguida en Europa, cuya práctica ascética era esencialmente la misma: el quietismo, encabezado por Miguel de Molinos, ${ }^{26}$ gran admirador del padre del alumbradismo mexicano, Gregorio López. $^{27}$

No obstante la evidente falta de información de los miembros del Tribunal para ligar el dexamiento de Zayas con los orígenes del alumbra-

23 Bataillon, 1966; Asensio, 2000.

24 Sobre el uso impreciso del término ver Jaffary, 2004,35 y 45. Tampoco aparece una distinción clara de los muchos usos del vocablo alumbrado a lo largo del estudio de Chuchiak, 2012.

25 Ver nota 16.

26 Miguel de Molinos (1627-1696), clérigo de Zaragoza, educado en Valencia por los jesuitas. Tellechea, 1987. No confundir con el jesuita Luis de Molina (1535-1600). Greengrass, 1998, 310.

27 «Molinist doctrine was unqualified Quietism. Its spirituality culminated in two fundamental themes: absolute passivity and contemplation in complete spiritual tranquillity. The soul must aim at 'mystic death', annihilation in God; allowing God to substitute Himself for the Ego and to dominate the whole being. The soul should have no desire, should make no act of love». Daniel-Rops, 1963, 372. Molinos fue admirador del padre del alumbradismo mexicano, Gregorio López, cuyas prácticas religiosas coinciden con la doctrina de los primeros alumbrados peninsulares. Milhou, 1992; también Chocano, 2000, 331. No compartimos la opinión de Huerga, 1986. Molinos y Gregorio López en Rubial, 1999, 124. El supuesto quietismo de otro heterodoxo contemporáneo de Zayas, Juan Félix Luna, Rubial, 2006, 223. 
dismo español de principios del XVI, al ocaso del XVII existieron ciertos parámetros de distinción entre las herejías, uno de ellos fue la categoría de vehemente. La cual suele relacionarse sólo con los «alumbrados» instruidos intelectualmente, escritores que abogaban por una religiosidad personal y ética. ${ }^{28}$ La clasificación de vehemente quizá esté señalando una primera frontera, por encima de la mistificación con la que el alumbradismo se importó desde España. Prueba de tal mistificación fue que el primer foco de «alumbradismo» mexicano ${ }^{29}$ se persiguiera, entre otras, por faltas de índole sexual. Evidenciando que desde entonces los inquisidores de México habían heredado la confusión doctrinal prevaleciente en la Península y llamaban «alumbrado» a cualquier infractor de la fe. Los inquisidores novohispanos desconocían que la célula originaria de alumbradismo surgido en torno a Isabel de la Cruz se caracterizó por su conducta intachable, ${ }^{30}$ a diferencia de los grupos posteriores, y arbitrariamente llamados alumbrados, de Sevilla, Extremadura o Llerena ${ }^{31}$ que fueron conocidos por su poca continencia sexual.

Nuestro trabajo plantea trascender las etiquetas que impusieron o ignoraron $^{32}$ los inquisidores, y no repetir su desaforada generalización, ni

28 Principalmente ver casos de Juan Félix de Luna (AGN, Inquisición, vol. 711) y Pedro García de Arias (AGN, Inquisición, vols. 429, 436 y 505), ambos referidos por Medina, 1987, Jaffary, 2004, y Rubial, 2006. A García se le atribuye haber sido un erasmista. En 1693, el principal denunciante de doña Ana hace mención al alumbrado García de Arias con relación a ella y a la coincidencia de que ambos fueran autores de obras místicas consideradas heréticas. AHN, Inquisición, 1731, exp.34, 99 .

29 Ver los casos en Jaffary, 2004, 29-33 y Dwyer, 1995.

30 Así lo reitera Márquez lo largo de su obra clásica (1980), e igualmente en trabajos posteriores (1989, 58); también Selke, 1952, 133.

31 En su amplio estudio, Jaffary observa que el conventículo y el mecenazgo de benefactores poderosos son características del alumbradismo español que prevalecieron en el alumbradismo mexicano y que estos se inspiran en las mismas fuentes de los alumbrados españoles. Pero nunca especifica qué fuentes ni a cuál de los diferentes grupos llamados «alumbrados» se refiere (Jaffary, 2004, 29-31). Tampoco Rubial en su obra, que tanto ha contribuido a la historia de la religiosidad novohispana, realiza ninguna distinción sobre el alumbradismo en su origen o sus manifestaciones tardías. No obstante que desde 1952, Selke ya venía proponiendo «examinar las diferencias fundamentales que separaron a los primeros alumbrados de los otros iluminados o de los diferentes brotes que surgieron posteriormente en diferentes provincias de España» (Selke, 1952, 136). Márquez afirma que no considera alumbrados a los grupos de Llerena, Extremadura ni Sevilla (Márquez, 1980, 58-64). Hamilton, igualmente, distingue «the three manifestations of iluminismo in 16th-century Spain: the group around Toledo, active between 1512 and 1535; that in Llerena in Extremadura, late 16th century; and that in Seville, the object of inquisitorial investigation in the 1620s». Sobre el abuso del término Hamilton, 1992, 123 y 155, respectivamente.

32 Ejemplo de ello es Gregorio López, quien nunca fue procesado por el Tribunal novohispano, a pesar de su evidente heterodoxia. 
sus prejuicios respecto al místico independiente de la institución religiosa. ${ }^{33}$ Por ello seguimos la propuesta que Hamilton aplica al fenómeno español y la extendemos a la Nueva España: solamente denominar dejados a los heterodoxos que practiquen el dexamiento ${ }^{34}$ distinguiéndolos de cualquier otro «alumbrado».

Ana de Zayas es una dejada. En numerosas ocasiones refiere que a partir de la suspensión del pensamiento, sosegada y quieta, recibe las revelaciones y el entendimiento de lo que debe hacer, negando su propia voluntad para efectuar sólo la de Dios, y especifica que negarse a sí mismo no es otra cosa que dexarse. ${ }^{35}$

La importancia de ello radica en que el dexamiento está ligado a profundas fuentes neoplatónicas, las cuales confluyen en la misma raíz del pensamiento hermético renacentista. ${ }^{36}$ Éste es el referente que Zayas retoma para los enigmáticos juegos de palabras y el lenguaje simbólico con el que ella se dirige a los sacerdotes de Puebla. Una misma fuente, el neoplatonismo, y dos diferentes manifestaciones: el dexamiento como práctica ascética personal y el lenguaje hermético para encubrir y revelar parcialmente un mensaje dirigido a un público selecto. ${ }^{37}$

33 Jaffary, 2004, 170.

34 Descripción del dexamiento, según los primeros alumbrados de España: «Que no tuviesen pensamientos de nada [...] y que para alcanzar aquella perfección y estado, en que la dicha persona alumbrada y otras de su calidad estaban, no había otra cosa, sino suspender todos los pensamientos y no pedir ni demandar nada a Dios bien ni mal, sino dexarse al amor de Dios; que dexándose a Dios, le enseñan todas las cosas...» (Llorca, 1980, 69). «En esta suspensión, no tenía necesidad de buscar más. Y que estando en esto desechase todos los pensamientos [...] y que era meritorio el trabajo que en desechar los tales pensamientos se tenía. Y que por esta manera daba Dios grandes conocimientos y enseñaba en el secreto del alma sin ruido de palabras ciencia maravillosa» (Selke, 1968, 246).

35 AHN, Inquisición, 1731, exp.34, 34v y 35. Compárese con las descripciones casi idénticas de los primeros alumbrados, citadas en la nota anterior.

36 Conjunto de diversas creencias basadas en la filosofía griega antigua, platónicas y presocráticas pitagóricas, principalmente, en las que se concibe una interrelación del mundo elemental-celestial y supracelestial. Yates, 1968, 254-255. «Astral body, that is the aethetic vehicle which the soul acquires from the various stars and spheres it passes through during its descent in to the earthy body. On this earth the vehicle, which began by being fine, shining and star-like, becomes heavy, dark and damp, and, unless purified and rendered more aetheric, it will at death drag down the soul to hell or to some lower incarnation. The astral body was for the Neoplatonists primarily a religious conception [...] or justification of theurgic practices, methods to approaching God and salvation which are non intellectual». Walker, 2003, 38-39. Ver nota 1.

37 La intencionalidad que persigue Zayas con sus escritos será abordada en un artículo próximo a publicarse, cuya complejidad es imposible abarcar en este trabajo que se limita a buscar sus fuentes doctrinales. 


\section{El Pseudo Dionisio Areopagita, teúrgia neoplatónica y ritual cristiano}

Como se ve, una misma línea filosófica comprehende la actitud sincrética, integradora, de las diferentes caras de la religiosidad de doña Ana. Incluso cuando ella nunca se habría autodenominado platónica, como no se llamaban a sí mismos platonistas muchos humanistas. ${ }^{38}$ Remontándonos a las raíces, recuérdese que en 1469 Ficino (1433-1499), después de haber sacado a la luz los escritos atribuidos a Hermes Trismegistus, supuesta fuente de enseñanza de Platón, publica sus traducciones de los tratados platónicos. La trascendencia de esta obra fue que Ficino recuperó en el filósofo griego la llave para el más importante conocimiento del hombre: que el principio divino e inmortal estaba en su propia alma ${ }^{39}$ Esta idea, ligada al dexamiento, en Zayas: «El reino de los cielos en vosotros está, y cuándo, cuando estamos vacíos de todo, cuando no queremos nada, nada porque nada es todo [...] En la letra D dice mi esposo, déjate»..$^{40}$

Abordemos ahora el citado fragmento desde el planteamiento de Antonio Márquez, cuya obra explica los orígenes del alumbradismo desde su causa filosófica. Márquez subraya la importancia del Pseudo Dionisio Areopagita ${ }^{41}$ como principal fuente del dexamiento y como punto de conexión con una tradición heterodoxa, más que cristiana, neoplatónica ${ }^{42} \mathrm{El}$ dexamiento se remonta a los textos escritos en griego y que aparecieron hacia el año 525 (mezcla del cristianismo sirio de finales del siglo $\mathrm{V}$ y el tardío neoplatonismo ateniense) atribuidos al supuesto discípulo de San Pablo, el Pseudo Dionisio Areopagita. ${ }^{43}$ Este autor es el fundador de la

38 Quienes, «like Plato, (who) believed that in educating a ruling elite lay the best hope of political and moral reform. A desire for harmony and hatred of dogmatism were among the deepest impulses of the age». Hankins, 1990, 7.

39 Lorh, 1990, 567-570.

40 AHN, Inquisición, 1731, exp. 34, 24v.

41 «En la investigación de los orígenes doctrinales del iluminismo, desde el punto de vista filosófico, todos los caminos conducen al Pseudo Dionisio». Lo cita en su proceso uno de los cabecillas, Alcaraz: «El dexamiento al amor de Dios que yo pretendía era tal que a los dejados ponía en la cumbre de la perfección que el glorioso san Dionisio pone de vía purgativa, iluminativa y unitiva». También ver testimonio de los dejados con relación al Areopagita: Márquez, 1980, 119-121 y 159-160; Hamilton (1992, 12-14) considera además a otros autores; la influencia del Areopagita en la mística renana, antecedente del alumbradismo español, en Turner, 2009.

42 «El amor de que los alumbrados nos hablan es el amor de Platón». Márquez, 1980, 166 y 174.

43 No está contemplado en el presente artículo entrar en el debate sobre el platonismo o cristianismo del Pseudo Dionisio, con relación al alumbradismo y los dejados, y para los fines de nuestra investigación, coincidimos con la famosa opinión de Lutero según la cual el Areopagita era más 
llamada «Teología negativa», que propone desprenderse de cualquier razonamiento discursivo para alcanzar el estado de contemplación mística. ${ }^{44}$

Pero el Pseudo Dionisio no es completamente original, sino que sigue al neoplatónico Proclo (412-485), ${ }^{45}$ para quien la dialéctica negativa no describe nada, en la teología negativa el Uno no tiene nombre y es una especie de teúrgia inmaterial. Mediante el silencio mental el teólogo o teúrgo negativo completa el estudio del Uno. Esta iniciación para Proclo se realiza mediante el silencio, superior a cualquier juicio o actividad cognitiva, el cual establece en el alma humana la secreta y desconocida naturaleza de los dioses. ${ }^{46}$

Este es el mismo principio que enseñaba hacia 1520 en España Isabel de la Cruz, fundadora de la secta alumbrada, y que daba a conocer gradualmente sólo a los iniciados o suficientemente instruidos en la virtud. ${ }^{47}$ Es también esencialmente la idea de Zayas y que, en párrafos anteriores, hemos citado: «Al punto me hallo sin especie de lo que pensaba, en una contemplación de sólo Dio sin que el entendimiento tenga facultad de discurrir».

El referente neoplatónico de Proclo y del Pseudo Dionisio puede ayudarnos a establecer conexiones entre el dexamiento y las frases de Zayas en torno al silencio, ya referidas al principio de este artículo:

Porque el que pierde el silencio pierde el juego (esto es, el que me dijere lo que siente) especialmente vuestra reverencia que es el que está muy cerca de entrarse en la puerta de mi corazón, y esta puerta tiene el umbral del silencio.

Doña Ana podría aludir al silencio mental o dexamiento y, paralelamente, estarse refiriendo a la idea de silencio asociada a guardar un secreto, lo cual nos remite también a las Epístolas del Pseudo Dionisio, ${ }^{48}$ donde

platónico que cristiano. La dimensión filosófica del Areopagita inserta en la tradición del pensamiento griego en De Andía, 2000, 363-394; Perl, 2007. Más interpretaciones en Klitenic y Myles, 2007; Rorem, 1993; Rorem y Lamoreaux, 1998, 99-138; Runia, 1991, 38. La influencia de San Pablo en el Areopagita: Stang, 2012.

44 Klitenic y Myles, 2007, 86.

45 La influencia de Proclo, documentada detalladamente por Burns, 2004, 119-121; también De Andia, 2000.

46 Burns, 2004, 121.

47 Al parecer, Ana de Zayas practica también los diferentes tipos de oración, además del dexamiento. La heterodoxia de Isabel de la Cruz no excluía prácticas ortodoxas como los tres niveles de oración: vocal, mental y supramental. A los principiantes aconsejaba oración y meditación en la pasión de Cristo, la suspensión intelectual sólo a los iniciados. Hamilton, 1992. Sobre estos diferentes grados en el camino de la contemplación en la teoría mística del Areopagita: Klitenic y Myles, 2007, 86.

48 Rorem, 1993, 18. Con relación al secreto también: Blum y Golitzin, 1990, 313. El secreto como medida de precaución antipoliciaca en los alumbrados, Márquez, 1980, 217. 
se aconseja preservar la enseñanza fuera del alcance de los profanos. La advertencia en Zayas podría tomarse igualmente como una medida de protección frente al Tribunal. Por el ambiente de tensión que la rodeó a ella y a sus mentores, como el jesuita Alonso Ramos.

Los referentes relativos al silencio se afincan en una tradición y en ella se halla también el nudo que une el eclecticismo de doña Ana. Para ejemplo sirva señalar que el erasmista español Juan de Valdés (1499- 1541), a quien Márquez considera el teólogo del inicial foco de alumbradismo, habla del amor de Dios en términos que suenan a la teoría neoplatónica del amor desarrollada en Florencia por Ficino. ${ }^{49}$ Los dejados hacen una interpretación del Pseudo Dionisio, que no es la de los autores escolásticos (Tomás de Aquino y Nicolás de Cusa), ${ }^{50}$ sino la lectura que sobre el Areopagita hizo Ficino, la cual fue adaptada y aceptada como acorde con el cristianismo desde el siglo XV. . $^{51}$

Si bien los neoplatonistas florentinos conservaron mucho del método y lenguaje del escolastismo, agregan su intenso interés por la dignidad y la libertad humana. ${ }^{52} \mathrm{Y}$ es precisamente con respecto a este último punto que Márquez observa que la libertad que los dejados buscaban a través del dexamiento era la del absoluto incondicionado, o de la Nada. ${ }^{53}$ Esto se explica desde la Dialéctica negativa que hemos revisado en Proclo, así como la idea de silencio mental, superior a toda actividad intelectual. Citando al Areopagita, Perl comenta «all things in all things and nothing in any... How namelessness coincides with all names and silence with the word»..$^{54}$

Estos conceptos los hemos visto ya en Ana de Zayas, ${ }^{55}$ quien repite un principio de los dejados, para quienes la libertad como virtud es la liberación del deseo. Cuando el hombre es totalmente libre de su deseo particular, coincide con el deseo universal y esto sólo se alcanza mediante la supresión

49 Gelder, 1964, 101. Alumbradismo y el platonismo de la Academia de Florencia: Bush, 1969, 195. Estas filosofías y el humanismo español del XVI: Elliott, 1965, 237-239.

50 Rorem, 1993, 239-240; también Pelican, 1987, 13-14.

51 Lorh, 1990, 567.

52 Mebane, 1989, 18.

53 Márquez, 1980, 223.

54 Perl, 2007, 16.

55 Ver nota 40. El tema lo he tratado ampliamente en Zayas, 2006 y 2007. La postura de nuestra alumbrada es paralela al quietismo contemporáneo a ella generado en Europa. «Mi deseo es no desear nada» escribió la quietista francesa Marie-Rosette, quien también produjo textos sobre la idea de perfección unida al concepto místico de la nada. Passmore, 1970, 132. 
total de los deseos individuales. Explica Márquez: «Esta es la ascética del dexamiento, no querer nada, no pensar en nada, no pedir nada...». ${ }^{56}$

Volviendo al Areopagita, recuérdese que su neoplatonismo aparece desde sus inicios como cristianizado. ${ }^{57}$ Fue gracias a ello que durante siglos el supuesto discípulo de San Pablo gozó de una gran aceptación teológica dentro del canon y se le consideró uno de los primeros referentes cristianos. ${ }^{58}$ Autores legitimados y que formaron parte del contexto cultural de Zayas, como Teresa de Ávila y Juan de la Cruz ${ }^{59}$ inspiran su misticismo en el Areopagita. Aún en Puebla, lo sigue también el jesuita irlandés Miguel Godínez (1591-1644) en su Teología Mística. ${ }^{60}$

Sobre éste último, con relación a Zayas, Godínez perteneció a la Compañía, fue confesor de afamadas monjas poblanas ${ }^{61} y$ de la misma Catarina de San Juan, sobre quien Alonso Ramos (también confesor de doña Ana) inspirara su obra censurada por la Inquisición. ${ }^{62}$ En este contexto, es altamente probable que Zayas tuviera noticia de la teología negativa del Pseudo Dionisio, o sus comentadores; sin embargo, su particularidad heterodoxa se evidencia cuando ella repetidas veces mezcla a tales figuras de autoridad con la mención explícita del dexamiento. Véase el siguiente fragmento:

Y por eso me enseña mi esposo Jesús, diciendo déjate, ha de dejarse el maestro si quiere acertar totalmente en las manos de Dios. Entendiendo que si entiende es porque Dios le da la luz, y atendiendo a que dice Jesús, Yo soy la luz del mundo; y cuando dice a sus ministros, vosotros sois luz del mundo, es porque se obliga a

56 Márquez, 1980, 199.

57 Klitenic y Myles, 2007, 3. Razones por las que los escritos dionisiacos fueron aceptados entre los cristianos de Oriente: Golitzin, 2003, 8-37.

58 El canon en términos metodológicos: textos doctrinales unificados, los cuales son prueba de los dogmas aceptados por la ortodoxia. Frei, 1974, 7-8 y 159. Los diferentes lectores del Pseudo Dionisio a lo largo de la Historia: Blum y Golitzin, 1990, 361.

59 La influencia del Areopagita en San Juan de la Cruz y Santa Teresa y en los mayores autores espirituales españoles del siglo XVI: Girón, 2009, 163-176.

60 Miguel Godínez enseñó filosofía en el colegio de San Jerónimo de Puebla, del que fue rector entre 1628 y 1631 y volvió a serlo de 1633 a 1638. O’Neill y Domínguez, 2001, 324. Godínez escribió la Práctica de la teología mística, editado en Puebla en 1681; en la página 37 de esta obra se habla del abandono a la voluntad divina, el concepto del dexamiento, pero obviamente sin llamarlo así. Su doctrina se apoya en el Pseudo Dionisio, San Agustín, Kempis, etc...

61 Como María de Jesús Tomelín (1579-1637), cuya vida inspiró una de las hagiografías novohispanas más divulgadas, e Isabel de la Encarnación (1594-1633). Myers, 2003, 49 y Loreto López, 2006.

62 Un primer acercamiento a un tema sobre el que seguimos trabajando: Zayas, Concepción, «Más preguntas sobre Catalina de San Juan, la alumbrada Ana de Zayas y sus mentores jesuitas (Puebla de los Ángeles 1688-1696)», próximo a publicarse. 
alumbrarlos, y si no los alumbra no verán palabra. Porque sólo la luz de Jesús entre las tinieblas luce como lo dice San Juan en el evangelio (lux in tenebris ${ }^{63}$ ) pero no por eso ha de dejar el maestro de estudiar, ${ }^{64}$ especialmente en el libro verdadero, que es Cristo, este libro hizo científico a San Buenaventura y no estudiaba en otro. Pero el leer en este libro es estudiar en imitar su inocente vida y de esta suerte el que quisiere y enseñare será grande en el Reino de los cielos. ${ }^{65}$

Efectivamente este padre de la Iglesia, como menciona Zayas, tiene un escrito titulado «Cristo, maestro único de todos». ${ }^{66}$ Con el comentario de doña Ana corroboramos que ella está citando aquí a un autor de lectura corriente entre los dejados; y cuya raíz doctrinal vuelve a conducirnos al Pseudo Dionisio ${ }^{67}$ o a sus comentaristas, como el cartujo Hugo de Balma. ${ }^{68}$ Estas obras ya se habían publicado en la Nueva España a finales del XVI $\mathrm{y}$, por lo menos media centena de ellas, fueron mandadas desde la Península a aquellas provincias a lo largo del siglo XVII. ${ }^{69}$

En el citado fragmento de doña Ana se relaciona el término dejarse con la idea de ser alumbrado, todo ello en un contexto semántico donde la autora está defendiendo su propia hermenéutica espiritual, siguiendo las mismas pautas de lectura de los dejados; es decir, subordinando las letras a la experiencia revelada. Es la misma hermenéutica del Pseudo Dionisio, cuyas enseñanzas afirman que las Escrituras se han estudiado, según la divina tradición, por una operación que trasciende el intelecto. ${ }^{70}$ Lo cual

63 Se refiere al pasaje evangélico, Juan, I, 5.

64 Coincide también con la línea erasmista, ver Avilés, 1980, 83.

65 AHN, Inquisición, 1731, exp. 34, 26.

66 Consúltese San Buenaventura, 1945. Este autor fue publicado tempranamente en México, ver Buenaventura, 1575 y su reedición de 1594. Sobre sus ideas de ciencia y filosofía McInerny, 1963, 699- 701.

67 Rorem, 1993, 238, y 2009, 71-84.

68 Márquez, 1980, 120 y 163, Huerga, 1986, 88. Por otra parte, el místico renano Taulero, al ensalzar la oración mental, siempre hace referencia a la Mística teología de Buenaventura. También el obispo Zumárraga cita el Sol de contemplativos aparecido por primera vez en España en 1514 y atribuido a Hugo de Balma, aunque muchos se lo adjudicaron a San Buenaventura. El colofón de tal obra dice así: «Aquí se acaba el presente libro llamado Mística Theulogía de Sant Dionisio». Zumárraga, 1994, 235. Sobre la influencia de Buenaventura y los místicos alemanes Ekchart y Taulero en la obra escrita del prelado de Puebla Juan de Palafox: Olivares, 2004, 163-165.

69 Más de setenta libros de San Buenaventura fueron enviados a la Nueva España a lo largo del XVII (AGI. Contratación, 1135,1142, 1144C, 1148 al 1151, 1156B, 1171, 1179, 1197, 1237). Agradezco a Pedro Rueda (Universidad Central de Barcelona), haberme proporcionado esta referencia. Diferentes lecturas, ortodoxa o heterodoxa, servían para dar distintas interpretaciones y usos de un mismo autor. Buenaventura es citado por los censores Sánchez y Trujillo en el proceso contra Zayas para señalar un error herético relacionado con la idea de predestinación. AHN, Inquisición, 1731, exp. 34, 11.

70 Areopagita, 1980, 123; Lorh, 1990, 556. 
repite la askesis neoplatónica, donde se insistió en que la sabiduría sólo se encontraba fuera de todo texto y fuera de todo lenguaje. ${ }^{71}$ Tal perspectiva aparece igualmente en Teresa y Juan de la Cruz, influenciados por el Areopagita. ${ }^{72}$ La novedad en una novohispana como Zayas es que ella asocie explícitamente todas estas ideas con el dexamiento.

Volviendo a la raíz, el dexamiento se remonta al planteamiento de Proclo e inspirado por éste, el Pseudo Dionisio identifica los sacramentos como ritos teúrgicos. El mismo Jesucristo opera como un símbolo teúrgico y la eucaristía como el rito teúrgico por antonomasia. ${ }^{73}$ Es relevante subrayar que Proclo fue también una fuente importante de la Teoría de la Magia renacentista, según la promovió Ficino. ${ }^{74}$ Tales antecedentes pudieron tener una incidencia en Ana de Zayas. En un texto que ya hemos analizado en otros trabajos, la «Danza moral o juego de maroma», ella describe el momento de su revelación justo después de comulgar y de escuchar la música de la iglesia. ${ }^{75}$ Bajo el referente del Pseudo Dionisio, el momento de la eucaristía en Zayas podría funcionar como un ritual teúrgico. Según nuestra interpretación de la «Danza moral...» y acorde con Ficino, la autora armoniza el platonismo con la autoridad «cristiana» del Areopagita, supuesto discípulo de San Pablo. ${ }^{76}$ Recordemos que el fundador de la Academia de Florencia en su De Christiana religione llegó a comparar a Jesucristo con el Areopagita ${ }^{77}$ y en De raptu Pauli retrata a San Pablo como un filósofo, explicando su rapto con reminiscencias platónicas a través de varios grados cósmicos. ${ }^{78}$ Así, en la «Danza Moral o Juego de Maroma» Zayas equipara al dexamiento con la Prudencia o máxima sabiduría según la refiere Platón. ${ }^{79} \mathrm{Si}$ bien doña Ana nunca menciona a Platón, ni al Areopagita, sí refiere a sus comentadores, como Buenaventura, y sobre todo el nexo de la autora con el Pseudo Dionisio (o habría que decir, ¿con Proclo?) se revela a través de la práctica heterodoxa del silencio mental o anulación de cualquier operación intelectual: dexamiento. Establecemos

71 Rappe, 2001, IX.

72 Girón, 2009, 169-171.

73 Burns, 2004, 126; las diferencias que separan al Areopagita de Proclo, en ibidem, 128 y 129.

74 Copenhaver, 1988a.

75 He realizado un extenso análisis de las fuentes platónicas de este escrito (Zayas, 2006).

76 Walker, 2003, 35; también Serracino-Inglott, 2001, 1-14.

77 «With the coming of Christ his disciples and followers were able to make sense of the law and the prophets. In a similar fashion, the Neoplatonic philosophers, Ficino's platonici, were able to use the best Christian interpreters, especially Dionysius the Areopagite». Hankins, 1990, 283.

78 Lauster, 2001, 46-47.

79 Ver Zayas, 2006. 
estas relaciones con el objetivo de ubicar la religiosidad de Zayas en un mismo universo metafísico, el cual fue utilizado por ella para integrar todas sus búsquedas espirituales:

El día de san Bartolomé fui a comulgar por el padre fray Bartolomé Guerrero, y díjele al Señor: dale a este padre un rayo de tu amor, para que sea un dechado perfecto. Vi que de un incendio que tenía en la mano derecha, soltó una centella en esta forma y se la echó al padre: que entendí que lo abrasaba, pero los efectos se verán, confío en Dios. La centella era así [dibujo de una estrella de ocho líneas]. Como estrella venía a ser con ocho rayos, hermosa, y me dijo ¿basta? Dije, sí, con un átomo de tu amor hay para encender infinitos mundos. ${ }^{80}$

De nuevo la comunión vuelve a funcionar como teúrgia que desata la visión y la recepción de la energía cósmica. Además, la referencia a los infinitos mundos recuerda la Teoría atomista de Giordano Bruno (De tripliciminimo, 1591), una obra que se ubica en el campo de la heterodoxia, la filosofía oculta, la magia y la ciencia. En el libro de Bruno el átomo representa un principio de inteligencia que refleja el infinito poder divino, ${ }^{81}$ como también doña Ana lo expresa en su visión.

\section{Kircher y los objetos filosóficos}

Tras los ejemplos que hemos referido hasta aquí, parece evidente que el lenguaje hermético de Zayas no fue un mero recurso literario y que comparte una misma línea de conocimiento con el Areopagita y Ficino: el ocultismo europeo. ${ }^{82}$ Una corriente que pervivió hasta el XVII en personajes como el ignaciano Kircher, ${ }^{83}$ éste relacionó al Pseudo Dionisio con Isis y Osiris. Antes, Ficino en su traducción de Los nombres divinos había dicho que el Areopagita y Hermes Trimegisto coincidían, entre otras cuestiones,

80 Al margen dice: Guerrero de amor es este padre (subrayado en el original). AHN, Inquisición, 1731, exp. 34, 3 .

81 «The absolute light within the atom becomes the principle of intelligence within the material world that makes the world intelligible by the mind. His concept of the atom as the physical minimum, which he places in a dialectical relationship with the infinite powerful maximus». Gatti, 2011, 81 y 288 .

82 Entendiendo por filosofía oculta una doctrina basada en la correspondencia de todas las cosas que existen y entre el mundo de lo divino, la naturaleza y el humano. Éste es un microcosmos o microtheos, se halla entre Dios y la naturaleza y tiene un papel primordial y dinámico entre aquellos dos. Ver notas 1 y 36 y Gibbons, 2001, 7-9.

83 Ziller, 2004, 321-323. 
porque ambos conciben a Dios como la nada y el todo ${ }^{84}$ Esta idea ya la hemos visto en Zayas. ${ }^{85}$

La influencia de Kircher en las mentes novohispanas más brillantes del XVII ha sido abundantemente estudiada con relación a Sigüenza y sor Juana $^{86}$ y aunque, a diferencia de ellos, Zayas nunca lo menciona (por lo menos no en los escritos que se conservan en los archivos inquisitoriales), e incluso desconocemos si ella pudo entender su latín, ${ }^{87}$ resulta probable que sus protectores jesuitas le proporcionaran canales de acceso al famoso hermetista. El colegio del Espíritu Santo de Puebla había sido el lugar donde se tuvo la primera colección de Kircher, este centro de conocimiento fue donde Alonso Ramos ejerció como rector en el tiempo que Zayas era su amiga, discípula o maestra... ${ }^{88}$

Con el antecedente kircheriano abordaremos algunos de los textos que doña Ana dirigió a los sacerdotes de su ciudad, ${ }^{89}$ los cuales tienen títulos relacionados con objetos científicos de la época..$^{90}$ He aquí una muestra: Espejo de confesores, Anteojo de larga vista, Compás, Escala de perfección, Reloj de sol, Linterna para la noche, Lámpara lúcida, Lumbrera elegante, Anteojos conservativos para la vista del alma, Espejo de lindos, Luces del día claro, Aguja de marear, Farol de negación, Reloj de arena, Espejo de claridad. ${ }^{11}$ Como ha observado Vermeir respecto a Kircher, sus experimentos hacen referencia a principios y estructuras ocultas según una concepción neoplatónica del universo y los instrumentos usados para estas prácticas pudieron considerarse mágicos y con significados aún velados

84 Yates, 1982, 124-127 y 418.

85 Ver nota 55.

86 Sin pasar por alto que Sigüenza llegó a criticar a Kircher y su interpretación de los códices mesoamericanos, pero también él afirma que un criollo puede entender mejor a Kircher que un europeo. Findlen, 2004, 343-349; Strasser, 2007.

87 Si bien en sus escritos Zayas refiere algunas frases en latín.

88 Tenemos incógnitas respecto a la relación de ambos. Sobre Kircher: Osorio, 1993; también Molina, 2004 y Findlen, 2004, 336-343.

89 Reiteramos un hecho que impide una contextualización más amplia de los escritos de la autora, ya que, desgraciadamente, se conservan pocos de ellos y sabemos que hubo muchos más por la referencia a sus títulos.

90 El relevante papel de los jesuitas como introductores de la Nueva Ciencia a finales del XVII en España: Navarro Brotóns, 2006, 390-404.

91 AHN, Inquisición, 1731, exp. 34, 13v. Sin soslayar el hecho de que las imágenes científicas aparecieron en la poesía española del XVII, como las registra también la novohispana sor Juana Inés de la Cruz. Sabat, 1999, 613; también Bénassy, 1999, 629-638. Nuestro estudio plantea que estos recursos poéticos en el caso de Zayas, van más allá de una mera expresión barroca, en desacuerdo con la idea de Vallejo, 2005. 
para nosotros. ${ }^{92}$ Igualmente para Zayas, los instrumentos que dan título a cada escrito podrían tener el valor de símbolos-objetos filosóficos, ${ }^{93}$ comunes a una tradición. Llama la atención que doña Ana coloque juntos, en un mismo título, al compás y a la escala, conocidos símbolos masones, y que otro de sus escritos se titule Reloj de arena. ${ }^{94}$

Kircher aparece con un compás en el frontispicio del Iter Exstaticum coeleste (1671), además de esta referencia, hemos reparado en el compás, la escala y el reloj de arena porque los tres elementos se encuentran en el grabado de la Melancolía I de Durero, una obra inspirada en el neoplatonismo de Ficino y la Oculta Filosofía de Agripa. Esos objetos simbolizan que el iniciado, al igual que el Arquitecto del Universo, debe aplicar a su trabajo las reglas de la matemática, según las concibe Platón. ${ }^{95}$ La Melancolía I de Durero representa teorías de micro y macro cosmos, armonía, entendidas en términos geométricos, así como profundos conocimientos de astrología y arquitectura. ${ }^{96}$

Por todos estos referentes, más que una simple floritura, parece evidente que Zayas alude a una tradición filosófica. En el siguiente escrito ella vuelve a presentar un experimento físico con relación a una visión de Dios:

En la oración vi a mi esposo Jesús, y díjele, Señor, toda he de ser luces, ¿y nada me das de fuego? Yo quisiera encender los corazones en tu amor. Mostróme en la mano derecha un incendio crecido de fuego de amor de Dios, y en la izquierda la Justicia, hecha de luz, y dijo aquí tengo el fuego, yo te lo daré a su tiempo, da ahora la luz. Dije, todo es hablar y no veo fruto. Dijo, la luz viene del sol, y con todo eso es fría, pero pon una yesca ${ }^{97}$ en un espejo, y ponlo al sol y verás cómo se enciende. Si todos pusieran de su parte la disposición, ${ }^{98}$ todos se encenderían. ${ }^{99}$

92 Vermeir, 2005, 138-159.

93 En la Royal Society de Inglaterra el telescopio, microscopio, etc. son llamados instrumentos filosóficos. Luthy, 2005, 111. Los objetos expuestos en el Museo de Kircher como símbolos de la correspondencia universal en Findlen, 1996, 85.

94 El Reloj de arena no aparece en la mencionada lista, pero es uno de los pocos escritos que sobrevive completo en el proceso inquisitorial. AHN, Inquisición, 1731, exp. 34, 20.

95 Panofsky, 2005, 157-171. Yates, 1999, 62.

96 Yates, 1999, 57. Recuérdese que Durero desde temprana edad se relacionó con círculos filosóficos devotos de Ficino y con humanistas locales de Nuremberg. Campbell, 1990, 70-71 y 117. En futuros trabajos ahondaremos en la posible formación que doña Ana pudo haber recibido de su padre, arquitecto.

97 Materia seca para encender con cualquier chispa, figurativamente lo que está dispuesto a encenderse, cualquier pasión o afecto.

98 La disposición con relación a la luna y el sol en fray Luis de Granada, 1946, 35.

99 La autora especifica que subraya las palabras transcritas directamente por revelación divina y en las que no ha intervenido su interpretación. AHN, Inquisición 1731, expediente 34, «De los diferentes papeles de Ana de Zayas», 16. Alonso Ramos, en su obra condenada por la Inquisición, hace múltiples 
Los profesores jesuitas novohispanos de finales del XVII promovían la teología de la ciencia media o scientia conditionata (cuyos tratados se escribieron casi totalmente entre 1667 y 1708). La cual postula que el ser humano tiene que cooperar, no basta la irradiación del amor divino, debe hacerse una elección por el bien y un esfuerzo. Según la asertiva reflexión de Kuri Camacho, tal pensamiento - llevado a sus últimas consecuencias- vendría a coincidir con la teología negativa del Pseudo Dionisio y con un pensamiento persistente del neoplatonismo cristiano ${ }^{100} \mathrm{O}$, como lo explicara el gran admirador del Pseudo Dionisio, Ficino: entendiendo la cooperación de cognición y amor como una interacción recíproca. ${ }^{101} \mathrm{Y}$ también con relación al Pseudo Dionisio, el citado escrito de Zayas recuerda aquél sentido teúrgico, que el Areopagita articuló en una variedad de términos neoplatónicos, especialmente apoyándose en el pensamiento de Proclo. ${ }^{102}$ Burns llama a esto «Symbolic technology», desarrollada de muchas maneras, como la animación de estatuas adornadas con símbolos selectos, recitación de himnos y oraciones, etc. Cuyo objetivo era acercar lo más posible al teurgista, alineándolo con lugares elevados del cosmos. ${ }^{103}$

Como ya mencionamos, estas prácticas ligadas al conocimiento mágico volvieron a tener vigencia en el Renacimiento, pervivieron hasta el siglo XVII y pudieron llegar a Zayas a través de Kircher ${ }^{104}$ En el epílogo de su Ars Magna lucis et umbrae (1646), cuya división por capítulos corresponde a la sefirot cabalística, Dios está simbolizado por el sol que, para los neoplatónicos, es la fuente de la emanación o luz absoluta. Esta emanación ocurre en diferentes etapas, simbolizada por la reflexión y refracción en espejos y lentes. ${ }^{105}$ Resulta interesante pensar que la figura de Jesucristo

referencias simbólicas al espejo, la más cercana al texto de Zayas es: «Sabida cosa es, experimentada, y referida, de Plinio, que los espejos cóncavos puestos a los rayos del sol, se encienden más fácilmente, que otro fuego cualquiera. Y Galeno añade, ser tradición que Arquímedes con unos espejos puestos a los rayos del sol abrasó las naves de una Armada enemiga». Ramos, 1689, 136; las otras referencias en 134-136.

100 El jesuita Antonio de Figueroa, llamado familiarmente abuela por doña Ana (AHN, Inquisición, 1731, exp. 34, 60v), promovió desde la cátedra y sus disertaciones filosóficas la scientia condicionata. Kuri Camacho, 2007, 110-111.

101 Lauster, 2001, 63.

102 Para Proclo «certain material objects in the natural world also held useful sympathetic relationships with higter principles... On the Hieratic Art Proclus argues these objects are symbols which elevate lower particulars in a certain to the level of their higher counterparts. One example he uses is that of the solar class, objects which have a relationship to the sun». Burns, 2004, 115.

103 Ibidem, 116.

104 Consultar Stolzenberg, 2004, 168; también Saussy, 2004. El hermetismo de Ficino y el cabalismo de Pico como referentes en la interpretación teosófica de Kircher: Veltri, 2009, 131 y 132. 105 Vermeir, 2005, 138. 
podría interpretarse desde esta tradición y no desde la ortodoxa. Así, el que Zayas retrate a Jesús como sol divino adquiere una dimensión neoplatónica que explicaría la referencia al experimento físico en el que la autora se apoya. ${ }^{106}$

Por otro lado el Ars Magna lucis, donde confluyen los experimentos físicos sobre la luz y la tradición cabalística, fue usada como argumento de veracidad de la aparición de la virgen de Guadalupe, lo cual comprueba que era una obra a la que muy probablemente Zayas tuvo acceso directa o indirectamente. ${ }^{107}$ Desde la óptica de una tradición común, el citado pasaje de doña Ana que alude a encender una yesca con el sol sobre un espejo, comparte también las referencias de la refracción de la luz Kircherianas que permean la «Primavera Indiana» (1680) de Sigüenza ${ }^{108}$ — a quien Brading describe suscribiendo doctrinas del hermetismo barroco-.$^{109}$

El símbolo del espejo es utilizado por Zayas para titular varios de sus textos, con relación al escrito antes citado del espejo puesto al sol, la segunda parte de éste podría confirmar una afinidad más con Kircher:

Lean el 'Espejo de claridad' vuestras reverencias, quizá Dios dirá algo a cada uno, y nadie tome por sí lo que yo escribo, que ya he dicho que mis palabras son como un espejo, que el que no tuviere una mancha en la cara no la verá en el espejo. ${ }^{110}$

En este fragmento Zayas describe su «Espejo de claridad» como una especie de oráculo que revelará algo diferente a cada sacerdote. En el diagrama cabalístico — con alusiones ocultistas- que Kircher incluye en el segundo volumen del Oedipus Aegyptiacus, la palabra espejo aparece unida a una antigua filosofía, la de la cábala, un sistema codificado tan respetado por Kircher como los jeroglíficos atribuidos a Hermes Trismegisto. ${ }^{111}$ Desde el Renacimiento el término cábala significa recepción, ${ }^{112}$ espejo y recepción parecen ser símbolos equivalentes para la novohispana, al igual que lo fueran para Kircher y toda una tradición donde, por ejemplo, caben

106 AHN, Inquisición, 1731, exp. 34, 25.

107 Findlen, 2004, 343. Ana de Zayas dedica uno de sus textos a la virgen de Guadalupe, AHN, Inquisición, 1731, exp. 34, 26v.

108 Findlen, 2004, 345. «Es casi innecesario insistir en que la Primavera indiana reúne las características de un poema neoplatónico [...] con elementos de la filosofía hermética». Mayer, 2002, 259; Trabulse, 2002, 94. También con relación a Kircher: Eagleton, 2010, 141-144.

109 Brading, 1991, 395-407.

110 AHN, Inquisición, 1731, exp. 34, 16.

111 Stolzenberg, 2004, 149 y 151.

112 Hebreo, 1989, 192. 
también otras asociaciones como las de Giordano Bruno. Éste relaciona las connotaciones mágicas de los símbolos egipcios con el lenguaje original de Dios, la cábala y el misticismo del Pseudo Dionisio. ${ }^{113}$

Como ha señalado Brading, este tipo de conocimientos fueron asimilados por muchos de los humanistas peninsulares que desde el XVI se establecieron en la Nueva España. ${ }^{114}$ Con relación a la cábala — como analizaremos más extensamente en publicaciones futuras-, Zayas describe que tenía una visión de la mano de Dios en medio de un círculo, donde se hallaban grabadas todas las letras del abecedario, como en las cartillas donde entonces se enseñaba a leer. El dedo índice le señalaba alguna vocal o consonante, otras veces sílabas, y así le eran reveladas las palabras que ella escribía. ${ }^{115}$ La descripción del círculo con letras o silabario combinatorio de Zayas resulta similar a la cábala sarracénica que aparece en el tomo segundo del Oedipus Aegyptiacus. ${ }^{116}$ Doña Ana hace referencia explícita a un código o clave necesarios para descifrar sus escritos, esto podría comprenderse mejor desde la perspectiva de sistemas codificados ocultistas como la cábala o el lenguaje hermético. Tendría que ver también con la hermenéutica revelada y con la idea de que sus escritos son un espejo, en el sentido que ofrecerán mensajes diferentes a cada receptor, como ya revisamos. En otro escrito de Zayas podemos leer:

Dice vuestra reverencia que claridad y oscuridad contradicen, es verdad, pero lo que para los discípulos de Cristo fue claro, para los fariseos fue oscuro. Hizo Dios de sus mismos ministros (que son todos los religiosos de este mundo) para que me labrasen a mí a un tiempo jueces y verdugos. Así lo digo en la «Mano de papel» y «Explicación de la batalla» [...] De manera que cada uno quisiera tener toda la luz de mi espíritu, y no tendrá sino la que Dios le diere [...] Cuando Cristo hablaba por parábolas eran éstas oscuras, pero no por eso eran malas. Cuando yo ya he hablado por metáforas han sido oscuras, pero no malas [...] Y finalmente no he de hablar claro hasta que amanezca el día en San Antonio. (Esto es) déjenme hablar y argüir con el padre fray José de Soto y que éste me dé trescientas vueltas y verán la luz de Dios, que la luz está en todas partes. ${ }^{117}$

113 Yates, 1982, 264-270.

114 Brading, 1991, 220.

115 AHN, Inquisición, 1731, exp. 34, 25v y 84. Sobre las cartillas: González del Campo, 1990, 182-183. Con la imprenta proliferaron unas cartillas que, además de enseñar a leer, incluían coplillas versificadas en estilo llano para memorizar datos esenciales sobre la doctrina cristiana. Bataillon, 1966, 534.

116 Kircher, 1652-1655, 377.

117 AHN, Inquisición, 1731, exp. 34, 74v. El texto nos remite al mismo tema del sol como fuente original de luz, también en el sentido neoplatónico. Ver nota 105. 
El que Zayas reitere que algunos de sus trabajos sí podían circular públicamente, ${ }^{118}$ no deja duda de que existían escritos suyos que debían guardarse en secreto. Esta heterodoxa del XVII sigue la tradición de los hombres renacentistas, entusiasmados por el famoso tratado de Apolo y sus mensajes ideográficos, «comprensibles en todo el mundo, pero sólo para los iniciados». ${ }^{19}$ Zayas sigue reproduciendo el sentido original del Hieroglyphica: como revelación y también como lenguaje velado.

Esto no es novedoso, ya que secreto y simbolismo se manifiestan de muchas formas en el período moderno temprano. La criptografía del siglo XVII ha sido abundantemente estudiada con relación a Europa ${ }^{120}$ y prácticamente ignorada en lo que respecta a la Nueva España. Esta cuestión está esperando ser abordada, y un punto de arranque podría ser la codificación y decodificación como uno de los temas más ampliamente tratados por Kircher, quien ofreció el supremo modelo de compatibilidad entre el catolicismo y la tradición hermética. ${ }^{121}$ Como se ha estudiado ampliamente, Kircher inspiró a las figuras intelectuales más importantes del XVII novohispano: sor Juana ${ }^{122}$ y Carlos de Sigüenza (1645-1700). No debe ser casual que con ambas mentes preclaras doña Ana tenga coincidencias importantes, como el haberse formado bajo el cobijo de los jesuitas y seguir la misma tendencia integradora, donde el conocimiento legitimado de los Padres de la Iglesia se mezcla con elementos herméticos.

Más que conclusiones, nuestra investigación plantea preguntas. ¿Habría que ampliar los radios de influencia del hermetismo de Kircher, unos radios que abarcaran la heterodoxia religiosa de una seglar educada por los jesuitas fuera de toda regla conventual, como fue Ana de Zayas? ¿Fue ella un caso aislado o existieron redes de conocimiento extraoficial que divulgaran este tipo de filosofías? Incluso respecto a Sor Juana y Sigüenza, habría que cuestionar si la semilla de Kircher no floreció más allá y llegó a tocar ámbitos políticos y religiosos aún por analizarse más profusamente. Porque parece evidente que el lenguaje hermético abarca también una dimensión de poder. Quizá en los diferentes discursos herméticos de esa sociedad, amante

118 Damos dos ejemplos, de los muchos que se registran en el proceso. «Este papel sí puede andar de mano en mano». AHN, Inquisición, 1731, exp. 34, 10v. «Doy licencia general a todas las personas que me han comunicado para que lo consulten entre sí, con secreto». Ibidem, 13v.

119 Panofsky, 2005, 173.

120 Vermeir, 2012, 29.

121 Findlen, 2004, 342.

122 Ver notas 18 y 19. 
del claroscuro, se escondan claves por develar al historiador actual. ${ }^{123}$ No en vano Kircher da tanta importancia al arte de mantener secretos, esta obsesión expresa algo más que una moda barroca, tiene que ver con arraigados principios sobre cómo hacer política, filosofía o vivir la religión. ${ }^{124}$

Con relación a Zayas y sus conocimientos de la filosofía ocultista, nos interesa subrayar que el modelo que subyace a la concepción de la religión en Kircher, por encima de su máscara católica, es un modelo basado en la metafísica neoplatónica e, incluso, que recuerda más al gnosticismo, que al cristianismo ortodoxo. ${ }^{125}$ Es en este punto donde coincide también el alumbradismo de Zayas, una forma de religiosidad que, como ya revisamos, se liga igualmente al neoplatonismo.

Según ha señalado Findlen, el sincretismo de Kircher derivó en un producto intelectual heterodoxo que amenazaba con desbordarse. ${ }^{126} \mathrm{La}$ alumbrada vehemente Ana de Zayas, alias la Serpiente, la Salamandra o la Paloma, pudo ser uno de esos productos desbordados... El análisis que aquí presentamos rescata sólo una parte de sus enigmáticos escritos, ella es igualmente sólo una pieza de una sociedad rica y también enigmática cuyas capas cultas se vieron atraídas por el hermetismo y sus corrientes afines, líneas filosóficas que confluyen en una misma esencia: su velo de oscuridad. ${ }^{127}$

Recibido el 13 de diciembre de 2013 Aceptado el 2 de junio de 2014

\section{Bibliografía}

Alatorre, Antonio: «En torno al Neptuno alegórico de sor Juana», Nueva Revista de Filología Hispánica, 58, 1, México, 2010, 269-278.

Areopagita, Pseudo Dionisio: Los nombres divinos y otros escritos, Barcelona, Bosch, 1980.

Asensio, Eugenio: El erasmismo y las corrientes espirituales afines, Salamanca, SEMYR, 2000 (primera edición 1952).

123 En el mismo contexto de Zayas, un mensaje velado detrás de la aparente floritura emblemática: Galí, 2008.

124 Vermeir, 2012.

125 Malcom, 2004, 303-306.

126 Findlen, 1996, 80.

127 Vermeir, 2012, 23. Findlen, 1996, 84. 


\section{CONCEPCIÓN ZAYAS}

Avilés, Miguel: Erasmo y la Inquisición. El libelo de Valladolid y la Apología de Erasmo contra los frailes españoles, Madrid, Fundación Universitaria Española, 1980.

Bataillon, Marcel: Erasmo y España. Estudios sobre la historia espiritual del siglo XVI, 2 vols., México, FCE, 1966.

Bénassy-Berling, Marié-Cécile: Humanismo y religión en sor Juana Inés de la Cruz, México, UNAM, 1983.

Bénassy-Berling, Marié-Cecile: «Sobre el hermetismo de sor Juana Inés de la Cruz», en Bosse, Mónika y otros (eds.), La creatividad femenina en el mundo barroco hispánico, Erfurt, Edition Reichenberger, 1999, vol. 2, 629-638.

Blum, Richard \& Golitzin, Alexander: The sacred athlete: on the mystical experience and Dionysios, its western world fountainhead, London, University Press of America, 1990.

Brading, David: Orbe indiano. De la monarquía católica a la república criolla, 1492-1867, México, FCE, 1991.

Burns, Dylan: «Proclos and the Theurgic Liturgy of Pseudo Dionysius», Dionysius, XXII, Halifax, December 2004, 111-132.

Bush, M.L.: Renaissance Reformation and the outer world: 1450-1660, New York, Harper \& Row, 1969.

Buxó, Pascual: «Función política de los emblemas en el Neptuno Alegórico», en Glantz, Margo (ed.), Sor Juana Inés de la Cruz y sus contemporáneos, México, UNAM-CONDUMEX, 1998, 245-255.

Campbell Hutchison, Jane: Albrecht Dürer a Biography, Princeton, Princeton University Press, 1990.

Cañizares Esguerra, Jorge: «Spanish America: From Baroque to Modern Colonial Science», en Porter, Roy (ed.), The Cambridge History of Science. Volume 4. Eighteenth-Century Science, Cambridge, Cambridge University Press, 2003, 718-737.

Chocano, Magdalena: La fortaleza docta. Élite letrada y dominación social en México colonial (siglos XVI-XVII), Barcelona, Edicions Bellaterra, 2000.

Chuchiak, John F.: The Inquisition in New Spain, 1536-1820: a documentary history, Baltimore, Johns Hopkins University Press, 2012.

Copenhaver, Brian: «Astrology and magic», en Schmit, C. B., Skinner, Q., Kessler, E. and Kraye, J. (eds.), The Cambridge History of Renaissance Philosophy, Cambridge, 1988a, 264-300.

Copenhaver, Brian: «Hermes Trismegistus, Proclus, and the question of a philosophy of magic in the Renaissance», en Merkel, I. \& Debus, A. (eds.), Hermeticism and the Renaissance: intellectual history and the occult in early modern Europe, London, Associated University Presses, 1988b, 79-110.

De Andía, Isabel: «Neoplatonismo y cristianismo en Pseudo-Dionisio Areopagita», Anuario Filosófico, 33, Navarra, 2000, 363-394. 
Dwyer, Daniel: Mystics in México: a Study of Alumbrados in Colonial New Spain (Tesis doctoral), Tulane University, New Orleans, 1995.

Eagleton, Catherine: Monks, Manuscripts and Sundials: The Navicula in Medieval England, Leiden, Brill, 2010.

Elliott, John H.: Imperial Spain 1469-1716, London, Edward Arnold, 1965.

Findlen, Paula: Possessing Nature: Museums, Collecting, and Scientific Culture in Early Modern Italy, Berkeley, University of California Press, 1996.

Findlen, Paula: «A Jesuit s Book in the New World. Athanasius Kircher and His American Readers», en Findlen, Paula (ed.), Athanasius Kircher: the last man who knew everything, London, Routledge, 2004, 329-364.

Frei, Hans: The eclipse of Biblical narrative: a study in eighteenth and nineteenth century hermeneutics, London, Yale University Press, 1974.

Galí Boadella, Montserrat: «El patrocinio episcopal en la ciudad de Puebla: el caso del obispo Manuel Fernández de Santa Cruz (1677-1699)», en Aranda, Ana María et. al, Barroco Iberoamericano. Territorio, Arte, Espacio y Sociedad. Actas del III Congreso Internacional del Barroco Iberoamericano, Sevilla, Universidad Pablo de Olavide, 2001, I, 89-110.

Galí Boadella, Montserrat: «Símbolos y jeroglíficos en el sepulcro de un príncipe: las piedras en un sermón fúnebre para el obispo poblano Manuel Fernández de Santa Cruz (1699)», en García, R. y Zuriaga, V. (eds.), Imagen y cultura. La interpretación de las imágenes como historia cultural, Valencia, Generalitat de Valencia, 2008, vol. I, 705-712.

Gatti, Hilary: Essays on Giordano Bruno, Princeton, Princeton University Press, 2011.

Gelder, H. A. Enno van: The Two Reformations in the $16^{\text {th }}$ Century. A Study of Religious Aspects and Consequences of Renassaince and Humanism, The Hague, Martinus Nijhoff, 1964.

Gibbons, Brian J.: Spirituality and the Occult: From the Renaissance to the Modern Age, London, Routledge, 2001.

Girón Negrón, Luis M.: «Dionysian Thought in Sixteenth-Century Spanish Mystical Theology», en Coakley, S. \& Stang, Ch. (eds.), Re-thinking Dionysius the Areopagite, Oxford, Wiley-Blackwell, 2009, 163-176.

Godwin, Joscelyn: Athanasius Kircher, A Renaissance Man and the Quest for Lost Knowledge, London, Thames \& Hudson, 1979.

Golitzin, Alexander: «Suddenly, Christ. The place of Negative Theology in the Mystagogy of Dionisius Areopagite», en Kessler, M. \& Sheppard, Ch. (eds.), Mystics. Presence and Aporia, Chicago, University of Chicago Press, 2003, 8-37.

González del Campo, M. ${ }^{a}$ Isabel: «Cartillas de la doctrina cristiana, impresas por la catedral de Valladolid y enviadas a América desde 1583», en Saranyana, Ignacio (ed.), Evangelización y Teología en América (siglo XVI), Pamplona, Universidad de Navarra, 1990, 181-193. 
González Rodríguez, Luis: «Juan María de Salvatierra y los seris, 1709-1710», Estudios de Historia Novohispana, 17, México, 1998, 229-262.

Gorman, Michael John: «The Angel and the Compass. Athanasius Kircher's Magnetic Geography», en Findlen, P. (ed.), Athanasius Kircher: the last man who knew everything, London, Routledge, 2004, 239-265.

Granada, Luis de: Introducción del Símbolo de la Fe [1583], Buenos Aires, Espasa-Calpe, 1946.

Greengrass, Mark: The European Reformation (1500-1618), London, Longman, 1998.

Griffiths, Paul: «Secrecy and Authority in Late Sixteenth and Seventeenth-Century London», The Historical Journal, 40-4, Cambridge, Dec. 1977, 925-951.

Hamilton, Alastair: Heresy and Mysticism in Sixteenth Century Spain: The Alumbrados, Toronto, University of Toronto Press, 1992.

Hamilton, Alastair: «The alumbrados: Dejamiento and its Practitioners», en Kallendorf, Hilaire (eds.), A New Companion to Hispanic Mysticism, Boston, Brill, 2010, 103-124.

Hankins, James: Plato in the Italian Renaissance, New York, Brill, 1990.

Hebreo, León: Diálogos de amor. Traducción de Garcilaso de la Vega [1590], Sevilla, Padilla Libros, 1989.

Hernández Palomo, José J.: «Acción misionera y espacio en México: un proyecto de división provincial», en Hernández Palomo, José J. y Moreno Jeria, R. (eds.), La Misión y los jesuitas en la América Española, 1566-1767, Sevilla, Escuela de Estudios Hispano-Americanos, CSIC, 2005, 87-115.

Huerga, Álvaro: Historia de los alumbrados. Vol. III. Los alumbrados de Hispanoamérica, Madrid, FUE, 1986.

Ingegno, Alfonso: «The New Philosophy of Nature», en Schmit, C. B., Skinner, Q., Kessler, E. \& Kraye, J. (eds.), The Cambridge History of Renaissance Philosophy, Cambridge, 1988, 236-263.

Jaffary, Nora: «La percepción de clase y casta en las visiones de los falsos místicos en el México colonial», Signos históricos, 8, México, julio-diciembre, 2002, 61-88.

Jaffary, Nora: False Mystics. Deviant Orthodoxy in Colonial Mexico, Lincoln, University of Nebraska Press, 2004.

Kircher, Athanasius: Oedipus Aegyptiacus, Roma, 1652-1655, vol. II.

Klitenic Wear, Sarah \& Myles Dillon, John: Dionysius the Areopagite and the Neoplatonist Tradition: Despoiling the Hellenes, Aldershot, Ashgate, 2007.

Kuri Camacho, Ramón: «Libertad divina y humana en algunos jesuitas novohispanos. Pedro de Abarca, Miguel de Castilla y Antonio de Figueroa Valdés», Estudios de Historia Novohispana, 37, México, UNAM, 2007, 91-122.

Lauster, Jörg: «Masilo Ficino as a Christian thinker: Theological aspects of his platonism», en Allen, M. \& Rees, V. (eds.), Marsilio Ficino: His Theology, His Philosophy, His Legacy, Leiden, Brill, 2001, 45- 69. 
Lavrin, Asuncion: Brides of Christ: Conventual Life in Colonial Mexico, Stanford, Stanford University Press, 2008.

Llorca, Bernardino: La Inquisición Española y los alumbrados (1509-1667), 3. ${ }^{\text {a }}$ ed., Salamanca, Universidad Pontificia, 1980.

Lo Sardo, Eugenio: «Kircher s Rome», en Findlen, P. (ed.), Athanasius Kircher: the last man who knew everything, London, Routledge, 2004, 51-64.

Loreto López, Rosalva: «Escrito por ella misma. Vida de la madre Francisca de la Natividad», en Lavrin, Asunción y Loreto López, Rosalva (eds.), La escritura femenina en la espiritualidad barroca novohispana, siglos XVII y XVIII, México, UDLA-AGN, 2002, 24-66.

Loreto López, Rosalva: «Los manuscritos confesionales. Un acercamiento a la mística novohispana», Estudios Humanísticos. Historia, 5, León, 2006, 93-119.

Lorh, Charles; «Metaphysics», en Schmit, C. B., Skinner, Q., Kessler, E. \& Kraye, J. (eds.), The Cambridge History of Renaissance Philosophy, Cambridge, 1988, 537-638.

Luthy, Christoph: «The confessionalization of Physics: Heresies, Facts and the Travails of the Republic of Letters», en Brooke, J. \& Maclean, I. (eds.), Heterodoxy in early modern science and religion, Oxford, Oxford University Press, 2005, 81-114.

Maclean, Ian: «Introduction», en Ibidem, X-XXI.

Márquez, Antonio: Los alumbrados. Orígenes y filosofía, Madrid, Taurus, 1980.

Márquez, Antonio: «El léxico de los primeros alumbrados. Historia y tipología», en Mancho Duque, María Jesús (ed.), En torno a la mística, Salamanca, Universidad de Salamanca, 1989, 57-63.

Mayer, Alicia: «El guadalupanismo en Carlos de Sigüenza y Góngora», en Mayer, Alicia (ed.), Carlos de Sigüenza y Góngora Homenaje 1700-2000, México, UNAM, 2002, vol. II, 243-272.

McInerny, Ralph: A History of western philosophy, London, University of Notre Dame Press, 1963.

Mebane, John S.: Renaissance magic and the return of the Golden Age: the occult tradition and Marlowe, Jonson, and Shakespeare, Lincoln, University of Nebraska Press, 1989.

Medina, J. Toribio: Historia del Tribunal del Santo Oficio, México, UNAM, 1987.

Milhou, Alain: «Gregorio López, el iluminismo y la Nueva Jerusalén americana», en Sarabia Viejo, M. ${ }^{a}$ Justina y otros (coords.), Europa e Iberoamérica: Cinco siglos de intercambios. Actas del IX Congreso Internacional de Historia de América, Sevilla, AHILA/Junta de Andalucía, 1992, vol. III, 55-83.

Molina, Michelle: «True Lies», en Findlen, P. (ed.), Athanasius Kircher: the last man who knew everything, London, Routledge, 2004, 365- 381. 


\section{CONCEPCIÓN ZAYAS}

More, Anna: «La patria criolla como jeroglífico secularizado en el Teatro de virtudes», en Mayer, A. (ed.), Carlos de Sigüenza y Góngora Homenaje 17002000, México, UNAM, 2002, vol. II, 47-77.

Morgan, Ronald J.: «Very good blood. Reconstructing the Asian Identity of Catarina de San Juan», en Morgan, R.J., Spanish American Saints and the Rhetoric of Identity 1600-1810, Tucson, University of Arizona Press, 2002, 119-142.

Myers, Kathleen: Neither Saints Nor Sinners. Writing the Lives of Women in Spanish America, Oxford, Oxford University Press, 2003.

Navarro Brotóns, Víctor: «Science and Enlightment in Eighteenth-Century Spain: The Contribution of the Jesuits before and after the Expulsion», en O'Malley, J.W., Bailey, G.A. \& Harris, S.J. (eds.), The Jesuits, Cultures, Sciences, and the Arts, 1540-1773, Toronto, University of Toronto Press Incorporated, 2006, vol. II, 390-404.

O’Neill, Charles y Domínguez, Joaquín: Diccionario histórico de la Compañía de Jesús. Bibliográfico temático, Roma/Madrid, Institutum Historicum/Universidad Pontificia Comillas, 2001, vol. II.

Olivares, Rocío: «El libro metágrafo de Alejo de Venegas y El sueño de Sor Juana: la lectura del universo», Anales del Instituto de Investigaciones Estéticas, 76, México, UNAM, 2000, 89-112.

Olivares, Rocío: «La espiritualidad alemana en la poesía del obispo Palafox», en Galí Boadella, Montserrat (coord.), La pluma y el báculo, Juan de Palafox y el mundo hispano del seiscientos, Puebla, BUAP, 2004, 161-188.

Olivares, Rocío: «The Eye of Imagination: Emblems in the Baroque Poem The Dream, by Sor Juana Inés de la Cruz», Emblematica. An Interdisciplinary Journal for Emblem Studies, 18, New York, 2010, 111-161.

Osorio Romero, Ignacio: La Luz Imaginaria. Epistolario de Atanasio Kircher con los novohispanos, México, UNAM, 1993.

Panofsky, Erwin: The life and Art of Albrecht Dürer, Princeton, Princeton University Press, 2005.

Passmore, John: The Perfectibility of Man, London, Duckworth, 1970.

Pelican, Jaroslav: «The Odyssey of Dionysian Spirituality», en Rorem, Paul et. al. contributors, Pseudo-Dionysius: The Complete Works, New Jersey, Paulist Press, 1987, 11-24.

Peña Espinosa, Jesús Joel: «Autores portugueses del siglo XVII para un obispo de Nueva España», Lusitania Sacra, 25, Lisboa, enero- junio 2012, 33-51.

Perl, Eric D.: Theophany. The Neoplatonic Philosophy of Dionysius the Areopagite, Albany, SUNY Press, 2007.

Ramos, Alonso: Prodigios de la omnipotencia y milagros de la gracia en la vida de la venerable sierva de Dios Catharina de San Joan. Natural del Gran Mogor, y difunta en esta imperial ciudad de Puebla, Puebla, Diego Fernández de León, 1689-1692. 
Rappe, Sara: Reading Neoplatonism: Non-discursive Thinking in the Texts of Plotinus, Proclus, and Damascius, Oxford, Oxford University Press, 2001.

Rorem, Paul \& Lamoreaux, John: John of Scythopolis and the Dionysian corpus: annotating the Areopagite, Oxford, Oxford University Press, 1998.

Rorem, Paul: «The Early Latin Dionysius: Eriugena and Hugh of St. Victor», en Coakley, S. \& Stang, Ch. (eds.), Re-thinking Dionysius the Areopagite, Oxford, Wiley-Blackwell, 2009, 71-84.

Rorem, Paul: Dionysius: A Commentary on the Texts and an Introduction to Their Influence, Oxford, Oxford University Press, 1993.

Rubial, Antonio: La santidad controvertida, México, FCE, 1999.

Rubial, Antonio: Profetisas y solitarios: Espacios y mensajes de una religión dirigida por ermitaños y beatas en las ciudades de Nueva España, México, FCE-UNAM, 2006.

Runia, David T.: «Witness or Participant? Philo and the Neoplatonic Tradition», en Vanderjagt, A. \& Pätzold, D. (eds.), The Neoplatonic Tradition: Jewish, Christian and Islamic Themes, Köln, Dinter, 1991, 36-57.

Sabat de Rivers, Georgina: «Imaginería mecánica en el "Sueño" de sor Juana», en Bosse, M. y otros (eds.), La creatividad femenina en el mundo barroco hispánico, Erfurt, Edition Reichenberger, 1999, vol. 2, 612-638.

San Buenaventura: Mistica theologia: en el cual se nos enseña el verdadero camino del cielo, mediante ejercicio de la virtud, México, Pedro de Balli, 1575.

San Buenaventura: Obras, Madrid, BAC, 1945, vol. I.

Saussy, Haun: «Magnetic Language. Athanasius Kircher and Communication», en Findlen, P. (ed.), Athanasius Kircher: the last man who knew everything, London, Routledge, 2004, 263-282.

Selig, Karl-Ludwig: «Algunos aspectos de la tradición emblemática colonial», Actas del Tercer Congreso Internacional de Hispanistas, Oxford, 1968, 831-837 <http://cvc.cervantes.es/literatura/aih/pdf/03/aih_03_1_091.pdf>.

Selke, Ángela: «Algunos datos nuevos sobre los primeros alumbrados. El edicto de 1525 y su relación con el proceso de Alcaraz», Bulletin Hispanique, 54, Bordeaux, Université de Bordeaux, 1952, 125-152.

Selke, Ángela: El Santo Oficio de la Inquisición. Proceso de fray Francisco Ortiz", Madrid, Guadarrama, 1968.

Sequeiros, Leandro: Athanasius Kircher 1601-1680. Ciencia y religión en el siglo XVII, 2010, <http://www.scribd.com/doc/>.

Serracino-Inglott, Peter: «Ficino the priest», en Allen, M., Rees, V. \& Davies, M. (eds.), Marsilio Ficino: His Theology, His Philosophy, His Legacy, Leiden, Brill, 2001, 1-14.

Stang, Charles: Apophasis and pseudonymity in Dionysius the Areopagite: 'no longer I', Oxford, Oxford University Press, 2012.

Stolzenberg, Daniel: «Four Trees, Some Amulets, and the Seventy-two Names of God. Kircher Reveals the Kabbalah», en Findlen, P. (ed.), Athanasius 


\section{CONCEPCIÓN ZAYAS}

Kircher: the last man who knew everything, London, Routledge, 2004, 149-169.

Strasser, Gerhard F.: «Out of synk: Athanasius Kircher's influence on Sor Juana's Writings», Barroco Journal, 1.2, July 2007, <http://www.revistabarroco.com/ volume_12>.

Tellechea Idígoras, Ignacio: Molinosiana, Madrid, BAC, 1987.

Trabulse, Elías: «La obra científica de don Carlos de Sigüenza y Góngora (16671700)», en Mayer, A. (ed.), Carlos de Sigüenza y Góngora Homenaje 17002000, México, UNAM, 2002, vol. I, 93-124.

Trabulse, Elías: Historia de la ciencia en México, México, CONACYT-FCE, vol. 3, 1997.

Turner, Denys: «Dyonisius and some late Medieval Mystical Theologians of Northern Europe», en Coakley, S. \& Stang, Ch. (eds.), Re-thinking Dionysius the Areopagite, Oxford, Wiley-Blackwell, 2009, 121- 135.

Vallejo Cervantes, Gabriela: «Ana de Zayas, de Puebla de los Ángeles. Los escorzos de una falsa beata», en Büschges, Ch. y Langue, F. (coords.), Excluir para ser. Procesos identitarios y fronteras sociales en la América Hispánica (XVII-XVIII), Estudios AHILA de Historia Latinoamericana, 1, Madrid/ Frankfurt, Iberoamericana/Vervuert, 2005, 137-161.

Veltri, Giuseppe: Rennaissance Philosophy in Jewish Garb: Foundations and Challenges in Judaism on the Eve of Modernity, Koninklijke, Brill, 2009.

Vermeir, Koen: «Openness versus Secrecy Historical and Historiographical Remarks», The British Journal for the History of Science, 45, Cambridge, Cambridge University Press, June 2012, 165-188.

Vermeir, Koen: «The magic of the magic lantern (1660-1700): on analogical demonstration and the visualization of the invisible», The British Journal for the History of Science, 38, Cambridge, Cambridge University Press, June 2005, 127-159.

Walker, Daniel P.: Spiritual and Demonic Magic: From Ficino to Campanella, Pennsylvania, Pennsylvania State University Press, 2003 [1958].

Wallace, William A.: «Traditional natural philosophy», en Schmit, C. B., Skinner, Q., Kessler, E. \& Kraye, J. (eds.), The Cambridge History of Renaissance Philosophy, Cambridge, 1988, 201-235.

Yates, Frances: Art, Science and History in the Renaissance, Baltimore, Charles S. Singleton, 1968.

Yates, Frances: Giordano Bruno and the Hermetic Tradition, London, Routledge \& Kegan Paul, 1982.

Zayas, Concepción: «La escritora Ana de Zayas y el obispo poblano Manuel Fernández de Santa Cruz», Anuario de Estudios Americanos, LVIII-1, Sevilla, 2001, 61-81.

Zayas, Concepción: «Danza moral o juego de maroma: religiosidad interior, filosofía ética y heterodoxia en Ana de Zayas, escritora seglar procesada por 
alumbradismo (Puebla de los Ángeles, México, siglo XVII)», en Lavrin, A. y Loreto López, R. (eds.), Diálogos espirituales. Manuscritos femeninos novohispanos. Siglos XVI-XIX, Puebla, BUAP/UDLA, 2006, 244-267.

Zayas, Concepción: «La recepción del neoplatonismo en la obra de la heterodoxa alumbrada Ana de Zayas», en Viforcos, M. ${ }^{a}$ Isabel y Loreto López, Rosalva (eds.), Historias compartidas. Religiosidad y reclusión femenina en España, Portugal y América. S. XV-XIX, León/Puebla, Universidad de León/BUAP, 2007, 211- 228.

Ziller Camenietzki, Carlos: «Barroque science between the Old and the New World. Father Kircher and His Colleague Valentin Stansel (1621-1705)», en Findlen, P. (ed.), Athanasius Kircher: the last man who knew everything, London, Routledge, 2004, 311-328.

Zumárraga, Juan de: Regla cristiana breve [1547], ed. de Ildefonso Adeva, Pamplona, Eunate, 1994. 